\title{
Synthesis and Characterization of Graphene Oxide from Coconut Husk Ash
}

\author{
A. SAHILA GRACE ${ }^{1 *}$ and G. S. PRABHA LITTIS MALAR ${ }^{2}$ \\ 1,2Department of Chemistry and Research Centre, Scott Christian College (Autonomous), \\ Nagercoil-629 003, (Affiliated to Manonmaniam Sundaranar University, Abishekapatti, \\ Tirunelveli- 627 012, Tamilnadu, India). \\ ${ }^{*}$ Corresponding author E-mail: sahilamuhu@gmail.com
}

http://dx.doi.org/10.13005/ojc/360220

(Received: February 23, 2020; Accepted: March 27, 2020)

\begin{abstract}
The main aim of the present work is synthesis and characterization of graphene oxide from the agricultural raw materials of coconut husks. Graphene oxide and carbon based other nanomaterials are unique in nature and broad range of applications because of its physical, chemical and electronic properties. Graphene oxide is an important carbon based two-dimensional nanomaterial. coconut husks is considered as an agro waste and evenly burned. The coconut husk ash contains high amount of silica was removed and the remaining portion of carbonized material of graphite is highly oxidized using sulfuric acid, sodium nitrate and potassium permanganate in order to increase oxygen functional groups. The oxidized form of graphene oxide hydrophilic in nature and it can be easily dispersed in water. The synthesized graphene oxide was characterized by FT-IR, FT- RAMAN, XRD and SEM-EDAX. FT-IR and Raman spectra indicated the presence of various oxygen functional groups such as in graphene oxide.
\end{abstract}

Keywords: Graphene oxide, Thermal combustion, Carbonized material, Exfoliated, Sodium silicate, Dispersible.

\section{INTRODUCTION}

Nowadays researchers have been developed the new production methods for synthesizing graphene oxide and carbon based nanomaterials using an environmental-friendly biomass resources ${ }^{1}$. Recycling carbon waste and converting it into graphene and graphene oxide may offer many economic and environmental benefits and may be used in many applications. Graphene oxide has a high surface area it can be used as electrode material for batteries, sensors, transistors, solar cells and conducting polymer composites. It is also used in many fields such as photo degradation, biodegradation, clean energy devices towards water purification and sterilization? ${ }^{2}$.

Graphene has two dimensional (2D) carbon allotrope with hexagonal lattice is held together by $\sigma$ bonds $^{3}$. Graphene attracted a great deal of recent scientific research because of their unique properties such as physical, chemical, thermal

This is an Open Access article licensed under a Creative Commons license: Attribution 4.0 International (CC- BY). Published by Oriental Scientific Publishing Company @ 2018

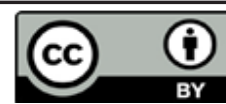


and other properties ${ }^{4}$. Oxidized form of graphene is called graphene oxide. Graphene oxide contains carbon based hexagonal rings with the hybridization of $\mathrm{sp}^{2}$ and $\mathrm{sp}^{3}$ carbon atoms and mainly graphene oxide containing functional groups are epoxide, carbonyls, hydroxyls and carboxylic ${ }^{5}$. This simple and low-cost synthesis of graphene oxide is renewable process could lead to give new opportunities for the production of graphene-based nanomaterials ${ }^{6}$. In order to promote a more competitive carbon based materials from the renewable resources of agriculture wastes.

Coconut husk is an inexpensive waste material that was to produce graphene oxide. Coconut husk is highly available economic value raw material. Many researchers employed different recycled wastes that may be returned into the valuable materials. coconut husk is the major agricultural products in south Indian countries like Kerala and Tamilnadu. coconut (Cocos nucifera) belongs to palm family. The plant coconut usually its fruit consists of three layers exocarp (outer skin), mesocarp (husky fibers) and endocarp (hard brown shell). coconut husk is the outer surface of coconut the fibrous husks have a number of uses and the fibers are separated to produce coir. coconut husks are used to make all kinds of household items such as rope, mats and brushes etc ${ }^{7}$.

The coconut husk wastes were burnt as fuel and as a source of activated charcoal which has potential as good adsorbent materials that can solve the waste water treatment ${ }^{8}$. The raw material of coconut husk ashes contains high amount of silica and also have carbon content ${ }^{9}$. Graphene oxide is synthesized by the oxidative treatment of carbonized graphite of coconut husk ash by using modified Hummer's method. The carbonized powder treated with potassium permanganate, concentrated sulfuric acid and sodium nitrate ${ }^{10,11}$. The attachment of the oxygen containing functional groups during the oxidation process increased and the suspension was ultra sonicated for specific periods of time ${ }^{12}$.

The present work focused for the synthesis of graphene oxide from coconut husk ash. The main motivation of utilizing these sources is to provide green and sustainable alternatives with low cost raw materials for large scale production of carbon based graphene oxide. Synthesized graphene oxide was characterized by various sophisticated techniques like FT-IR, FT-Raman, XRD, SEM-EDAX.

\section{MATERIALS AND METHODS}

\section{Materials}

Coconut husk was collected from local area in Kanyakumari district, Tamil Nadu, India. Chemicals were purchased from Merck (AR grade) and were used without purification: sodium hydroxide $(\mathrm{NaOH})$, sulfuric acid $\left(98 \% \mathrm{H}_{2} \mathrm{SO}_{4}\right)$, sodium nitrate $\left(\mathrm{NaNO}_{3}\right)$, potassium permanganate $\left(\mathrm{KMnO}_{4}\right)$, hydrogen peroxide $\left(30 \% \mathrm{H}_{2} \mathrm{O}_{2}\right)$, hydrochloric acid $(5 \% \mathrm{HCl})$ and deionized (DI) water.

\section{Alkali Extraction}

Coconut hush was collected, cleaned and dried. Coconut hush was treated by thermal combustion under controlled condition at $700^{\circ} \mathrm{C}$. $5.0 \mathrm{~g}$ of coconut husk ash and $50 \mathrm{~mL}$ of $2 \mathrm{M}$ sodium hydroxide solution was poured into a beaker and stirring for $4 \mathrm{~h}$ at $70^{\circ} \mathrm{C}$ using hotplate magnetic stirrer. After that, the solution was filtered by using Whatman No. 41 ashless filter paper the filtrate solution was discarded. The residue of carbonized material was collected used as the synthesis of graphene oxide.

\section{Graphene Oxide Synthesis}

The prepared carbonized material was washed several times by using $\mathrm{HCl}$ and water then dried in an air oven. For this process $1 \mathrm{~g}$ of the above powder was dissolved into $50 \mathrm{~mL}$ of concentrated $\mathrm{H}_{2} \mathrm{SO}_{4}$ under stirring in an ice bath at $5-10^{\circ} \mathrm{C}$ for $3 \mathrm{~h}$ after added $0.5 \mathrm{~g}$ of $\mathrm{NaNO}_{3}$ poured into the solution continuously stirred for 2 hours. Add $3 \mathrm{~g}$ of $\mathrm{KMnO}_{4}$ was very slowly added into the solution to keep the temperature below $15^{\circ} \mathrm{C}$ under constant stirring for 3 hours. Then it was warmed at room temperature stirred continuously in a water bath at $35^{\circ} \mathrm{C}-40^{\circ} \mathrm{C}$ for 1 hours. The prepared solution was diluted by $30 \mathrm{~mL}$ of deionized water.

During the dilution, the temperature was controlled to be greater than $60^{\circ} \mathrm{C}$ and stirring along with $1 \mathrm{~h}$ followed by $4 \mathrm{~mL}$ of $\mathrm{H}_{2} \mathrm{O}_{2}(30 \%)$ was added turning the colour changed from brown to dark yellow and additionally diluted by $200 \mathrm{~mL}$ deionized water. The residual acids and impurities of the solution removed completely by centrifugation for 30 min washed with water. Finally, the yellowish brown color suspension was ultrasonicated for $30 \mathrm{~min}$ and dried. 


\section{RESULTS AND DISCUSSION}

The synthesized pure graphene oxide from the ashes of coconut husk by modified Hummer's method and characterized by using various sophisticated analytical techniques FT- IR, FT- Raman, XRD and SEM- EDAX.

\section{Fourier-transform infrared spectroscopy (FT-IR)}

FT-IR spectrum of GO shown Fig. 1 confirms the functional groups are present in graphene oxide such as hydroxyl, epoxy, and carbonyl groups ${ }^{13}$. The strong peak around 3418 $\mathrm{cm}^{-1}$ attributed to the stretching mode of $\mathrm{O}-\mathrm{H}$ bond, reveals the presence of hydroxyl group in $\mathrm{GO}^{14,15}$. Weak bands at $2604 \mathrm{~cm}^{-1}$ and $2484 \mathrm{~cm}^{-1}$ were due to symmetric and asymmetric stretching vibration of $\mathrm{C}-\mathrm{H}$ bond respectively. The peak at $1738 \mathrm{~cm}^{-1}$ represent carbonyl $\mathrm{C}=\mathrm{O}$ and the peak at $1632 \mathrm{~cm}^{-1}$ arises from aromatic $\mathrm{C}=\mathrm{C}$ stretching group. The peak at $1287 \mathrm{~cm}^{-1}$ denotes $\mathrm{C}-\mathrm{O}-\mathrm{C}$ stretching and the peak at $1071 \mathrm{~cm}^{-1}$ corresponds to the vibrational mode of the $\mathrm{C}-\mathrm{O}$ group this peaks confirms the functional groups are present in $\mathrm{GO}^{16}$. The peak at $1177 \mathrm{~cm}^{-1}$ denotes C-O-C stretching vibration ${ }^{17}$. This FT-IR study proved that the synthesized graphene oxide hydrophilic in nature due to the presence of oxygen functional groups.

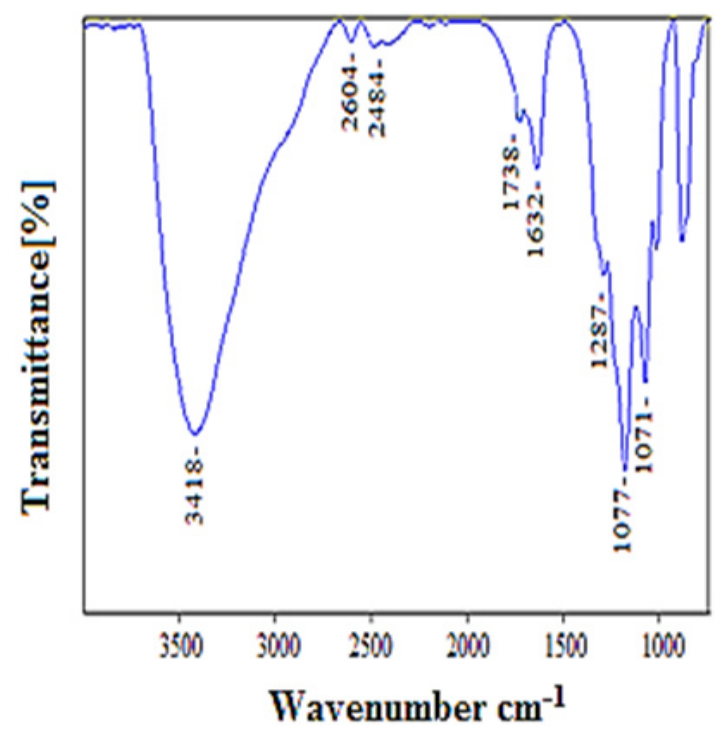

Fig. 1. FT- IR spectrum of graphene oxide

\section{FT- Raman spectrum}

The Raman spectrum of GO shown in Fig. 2 the spectra of the GO made from coconut husk displayed two prominent peaks at $1595.89 \mathrm{~cm}^{-1}$ and $1378.89 \mathrm{~cm}^{-1}$. In this work, Raman spectrum was used to determine the number of graphene oxide layers ${ }^{18}$. The first peak $D$ band (ID) at $1378.89 \mathrm{~cm}^{-1}$ and the second peak $\mathrm{G}$ band (IG) at $1595.89 \mathrm{~cm}^{-1}$. The first peak attributed to local defects found at the edges of the grephene sheets and the second peak was represents the $\mathrm{sp}^{2}$ carbon hybridization in the observed multilayer stacks. The ratio between the intensities of these bands indicates the quality of the product ${ }^{19}$. The band intensity ratio $I D / I G=0.86$, the prominent $D$ band for $G O$ clearly indicates the presence of structured imperfections induced by attachment of hydroxyl and epoxide groups. The peak at $2687.73 \mathrm{~cm}^{-1}$ is corresponding to the $2 \mathrm{D}$ band which can be useful to determine the intensity of that peak seems to be related to the number and orientation of graphene layers.

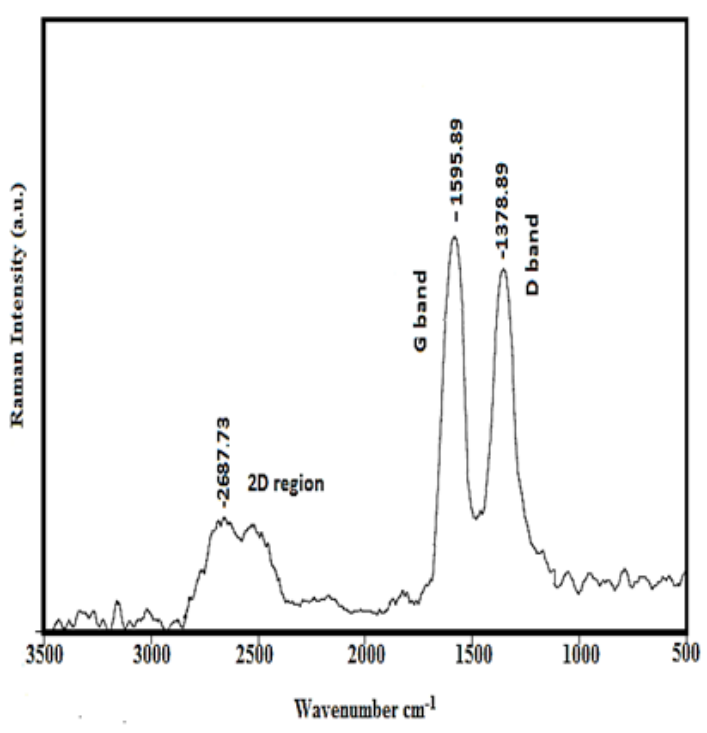

Fig. 2. FT- Raman spectrum of graphene oxide

\section{X-Ray Diffraction (XRD)}

The X-Ray Diffraction (XRD) patterns of GO is shown in Fig. 3. The XRD analysis observed crystalline structure of the GO sample. The GO sample shows a sharp peak at $2 \theta=10.13^{\circ}$ in the XRD pattern corresponds to (001) plane which may be attributable to an increase in the interlayer spacing due to oxygen containing functional groups on the graphene oxide surface ${ }^{20}$. The average crystalline size of GO sample was calculated by using Scherrer's formula $D=K \lambda / \beta \cos \theta$.

Where, $\mathrm{D}=$ crystallites size $(\mathrm{nm}), \mathrm{K}=0.9$ (Scherrer constant), $\lambda=0.15406 \mathrm{~nm}$ (wavelength of the $\mathrm{X}$-ray sources), $\beta=\mathrm{FWHM}$ (radians), $\theta=$ peak position (radians). 
Here $\mathrm{K}=0.9, \lambda=0.1540 \mathrm{~nm}$, is the X-ray wave length and $\beta$ is the full width at half peak heigh. $\beta$ $=0.2362,2 \theta=10.130, \theta=5.0650$. The average size of the graphene oxide calculated approximately $0.14 \mathrm{~nm}$.

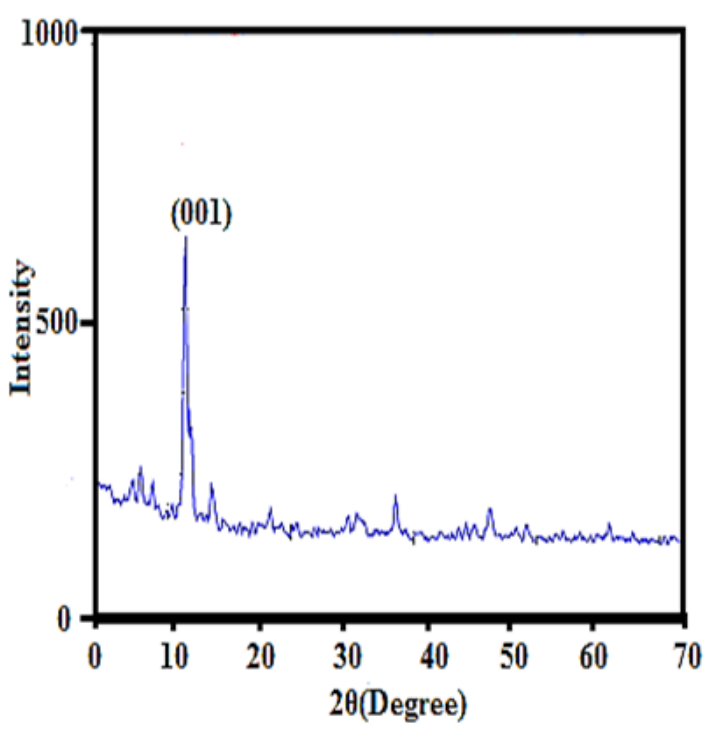

Fig. 3. X -Ray Diffraction (XRD) of graphene oxide

\section{Scanning Electron Microscope (SEM)}

Scanning electron microscopy supported to provide the surface morphology and the structure of nanomaterials. Fig. 4 shows the surface morphology of the graphene oxide sample. The SEM image proved that the flat surface with ordered layer structure of graphene oxide. This image conforms the graphite oxide oxidized and formed the number of oxide layers. The graphene oxide reveals randomly aggregated thin, crumpled layers structure.

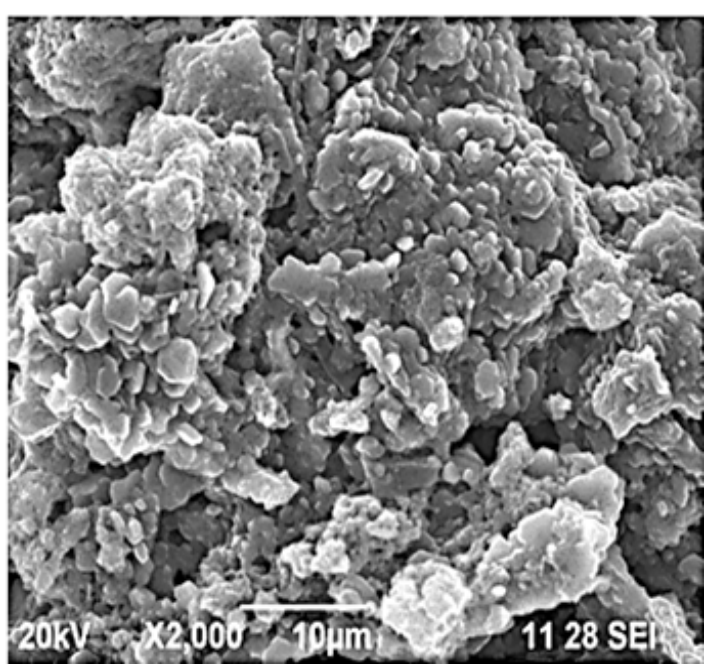

Fig. 4. SEM image of graphene oxide

\section{Energy- Dispersive X- ray Spectroscopy (EDX)}

An energy dispersive $\mathrm{X}$-ray analysis is used for identifying the elemental composition of the specimen. EDX image of Fig. 5 shows that the graphene oxide contains the elements such as oxygen and carbon. The first peak at $k \alpha 0.278$ $\mathrm{keV}$ corresponds to carbon and the second peak at $\mathrm{k} \alpha 0.701 \mathrm{keV}$ corresponds to oxygen. A weight percentage and atomic percentage of carbon and oxygen found to be 33.63:66.37 and 31.80:68.18. The EDX data predict the presence of carbon and oxygen in the graphene oxide sample.

Table 1: EDX Data of graphene oxide from CHA

\begin{tabular}{cccc}
\hline SL. No & Element & Weight\% & Atomic \% \\
\hline 1 & oxygen & 66.37 & 68.18 \\
2 & carbon & 33.63 & 31.82 \\
\hline
\end{tabular}

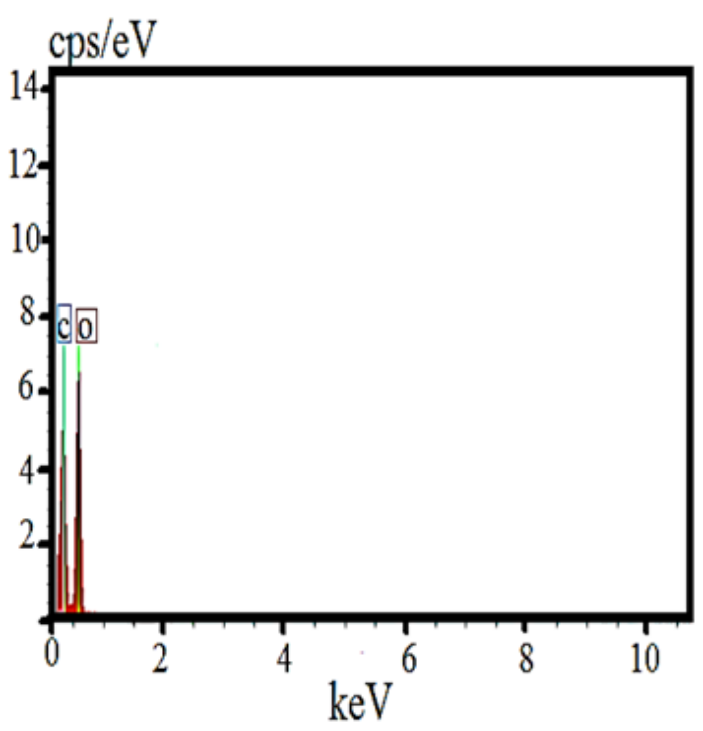

Fig. 5. EDX spectrum of graphene oxide

\section{CONCLUSION}

As described in this work, we can conclude that it is possible to synthesis graphene oxide using coconut husk as a raw material. FT-IR spectrum confirmed that the GO had some oxygen functional groups. Raman spectrum confirmed that presence of graphitic structure and the intensity ratio $\mathrm{ID} / \mathrm{IG}$ is around 0.86 which is compared to reduced graphene oxide the intensity ratio ID/IG is usually more than one. The synthesized graphene oxide can be potentially used for many applications. 


\section{ACKNOWLEDGEMENT}

We thank our colleagues from who provided the chemicals and laboratory facilities Department of Chemistry and research centre, Scott Christian College
(Autonomous), Nagercoil, Tamil Nadu, India.

\section{Conflict of interest}

The authors declare no conflict of interest.

\section{REFERENCES}

1. Ismail, M.S.;Yusof, N.; Yusop, M.Z.M.; Ismail, A.F.; Jaafar, J.; Aziz, F.; Karim, Z.A.; Mal. J. Fund. Sci., 2019, 15, 516-521.

2. Somanathan, T.; Prasad, K.; Ostrikov, K.; Saravanan, A.; Krishna, V.M. Nanomater., 2015, 5, 826-834.

3. Al-Gaashani, R.; Najjarc, A.; Zakariaa, Y.; Mansoura, S.; Atieha, M.A.; Ceram. Int., 2019, 45, 14439-14448.

4. Yi, G.; Xing, B.; Zeng, H.; Wang, X.; Zhang, C.; Cao, J.; Chen, L. J Nanomater., 2017, 1-10.

5. Bo, Z.; Shuai, X.; Mao, S.; Yang, H.; Qian, J.; Chen, J.; Yan, J.; Cen, K. Sci Rep., 2014.

6. Singh, P.; Bahadur, J.; Pal, K. Graphene., 2017, 6, 61-71.

7. Abrahim, B.N.; Homenauth, O. Agronomy Sci. Biotechnol., 2019, 5, 97-103.

8. Anuar, M.F.; Fen, Y.W.;Zaid, M.H.M.; Matori, K.A.; Khaidir, R.E.M. Results. Phys., 2018, 11, 1-4.

9. Supriyanto, G.; Rukman, N. K.; Nisa, A. K.; Jannatin, M.; Piere, B.; Abdullah, A.; Fahmi, M. Z.; Kusuma, H. S. BioResour., 2018, 13, 4832-4840.

10. Johra, F.T.; Lee, J.; Jung, W. J Ind Eng Chem.,
2014, 20, 2883-2887.

11. Narasimharao, K.; Ramana, G.V.; Sreedhar, D.; Vasudevarao, V. J. Mater. Sci. Eng., 2016, 5, 3000-3035.

12. Paulchamy, B.; Arthi, G.; Lignesh, B.D. J Nanomed Nanotechnol., 2015, 6, 85-95.

13. Bera, M.; Chandravati, Gupta, P.; Maji, P.K. J. Nanosci. Nanotechnol., 2018, 18, 902-912.

14. Ding, S.; Sun, S.; Xu, H.; Yang, B.; Liu, Y.; Wang, H.; Chen, D.; Zhang, R. Mater. Chem. Phys., 2019, 221, 47-57.

15. Shen, J.; Shi, M.; Li, N.; Yan, B.; Ma, H.; Hu, Y.; Ye, M. Nano. Res., 2010, 3, 339-349.

16. Ciplak, Z.; Yildiz, N.; Calimli, A. Nanotubes and Carbon Nanostructures., 2014, 23, 361-370.

17. Chen, J.;Yao, B.; Li, C.; Shi, G. Carbon., 2013, 64, 225-229.

18. Jugade, R.M.; Sharma, S.; Gokhale, S. Materials Science-Poland., 2014, 32, 243-246.

19. Li, F.; Song, J.; Yang, H.; Gan, S.; Zhang, Q.; Han, D.; Ari Ivaska, A.; Niu, L. Nanotechnol., 2009, 20, 326-340.

20. Kartick, B.; Srivastava, S.K.; Srivastava, I. J. Nanosci. Nanotechnol., 2013, 13, 4320-4324. 